\title{
Platelet Activation In Mice and Human Helicobacter Pylori Infection
}

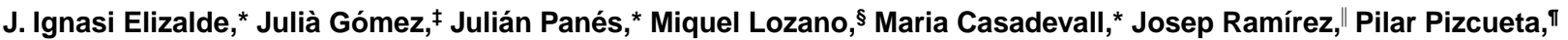 \\ Francesc Marco, ${ }^{\ddagger}$ Francisco Díaz de Rojas, ${ }^{\star \star}$ D. Neil Granger, ${ }^{\ddagger \neq}$ and Josep M. Piqué ${ }^{\star}$

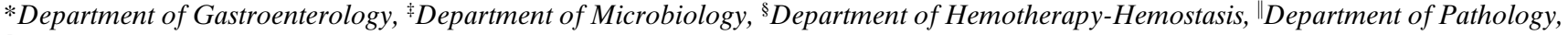 \\ ${ }^{\mathbb{L}}$ Liver Unit, Hospital Clínic i Provincial, University of Barcelona, 08036 Barcelona, Spain; **Medical Department, Schering-Plough, \\ 28046 Madrid, Spain; and ${ }^{\ddagger}$ Department of Physiology, LSU Medical Center, Shreveport, Louisiana $71130-3932$
}

\begin{abstract}
Extracts of Helicobacter pylori (HP) have been shown to induce leukocyte adhesion in mesenteric venules, but the effects of HP infection on gastric microvessels are unknown. Inflammatory cell interactions in the gastric microcirculation were studied by intravital videomicroscopy in mice inoculated with either saline or fresh isolates of HP. Platelet aggregates were detected and quantified in murine portal blood, while endothelial P-selectin expression was determined using the dual radiolabeled $\mathrm{mAb}$ technique. Platelet activation and aggregation were studied in HP-infected patients and controls by measuring the platelet-aggregate ratio and platelet $\mathrm{P}$-selectin expression.

HP infection induced a marked increase in the flux of rolling leukocytes and the appearance of platelet and leukocyteplatelet aggregates in murine gastric venules. The HP-induced rolling and platelet aggregate formation was abrogated by mAbs against L- or P-, but not E- selectin. Endothelial cell expression of P-selectin was not altered, but platelet P-selectin expression was enhanced in HP-infected mice. Circulating platelet aggregates and activated platelets were also detected in HP-infected patients. These findings indicate that platelet activation and aggregation contribute to the microvascular dysfunction and inflammatory cell recruitment associated with HP infections. (J. Clin. Invest. 1997. 100: 996-1005.) Key words: platelet activation - inflammation • platelet-leukocyte aggregation $•$ peptic ulcers
\end{abstract}

\section{Introduction}

During the past decade, the gram-negative bacterium Helicobacter pylori $(\mathrm{HP})^{1}$ has been identified as one of the most prevalent infectious agents in man (1). In addition to its well recognized role as a mediator of gastritis, peptic ulcer, and gastric neoplasia, HP has also been implicated in the pathogenesis of cardiovascular diseases (2-4). The latter observations support

Address correspondence to Josep M. Piqué, Gastroenterology Department, Hospital Clínic i Provincial, Villarroel 170, 08036 Barcelona, Spain. Phone: 34-3-227-54-18; FAX: 34-3-451-68-77; E-mail: pique@ medicina.ub.es

Received for publication 4 December 1996 and accepted in revised form 19 June 1997.

1. Abbreviations used in this paper: $\mathrm{HP}$, Helicobacter pylori; $\mathrm{PE}$, phycoerythrin; PFA, paraformaldehyde.

J. Clin. Invest.

(c) The American Society for Clinical Investigation, Inc. 0021-9738/97/09/0996/10 \$2.00

Volume 100, Number 5, September 1997, 996-1005

http://www.jci.org the view that HP may exert some of its effects on the gastric mucosa through an action on the vascular supply.

Several factors have been implicated in the pathogenesis of HP infection, either dependent on the bacterial strain or on the host immune response (5). HP may produce substances that directly injure epithelial cells (6), thereby reducing the resistance of the mucosa to gastric injury. In vitro evidence suggests that HP may also indirectly induce gastric damage by stimulating epithelial cytokine (mainly IL-8) responses (7). Furthermore, extracts of HP contain substances that elicit chemotactic activity in neutrophils and monocytes, and that can increase the surface expression of some adhesion molecules on isolated granulocytes (8-13). Limited observations in vivo also support a role for inflammatory cells in the development of HP-induced gastric mucosal damage. Two recent studies in rats that monitored inflammatory cell responses in mesenteric venules superfused with HP extracts have demonstrated an enhanced adhesion and emigration of leukocytes, increased vascular albumin leakage, mast cell degranulation, and platelet-leukocyte aggregation $(12,14)$. A weakness of these studies is that direct exposure of mesenteric venules to HP extracts may not adequately mimic the inflammatory events associated with chronic gastric infection.

Recently, a mouse model of HP infection was described that mimics several aspects of the human disease process (15). This model affords an opportunity for studies of the in vivo gastric responses to chronic infection without the need for special animal conditions (i.e., germ-free or athymic animals). This study used this mouse model in an effort to characterize the inflammatory responses elicited by chronic HP infection in the gastric microcirculation. For that purpose, we have adapted the technique of intravital fluorescence microscopy to investigate the effects of chronic HP infection on leukocyte-plateletendothelial cell interactions in gastric submucosal venules.

Selectins, in contrast to other adhesion molecules, are restricted to the vascular system where they mediate the initial attachment of leukocytes to endothelial cells, allowing leukocytes to roll along the venule wall before establishing firm adhesion (16). P-selectin is expressed on the surface of activated endothelial cells and platelets, in the latter instance contributing to platelet adhesion and aggregation (17). One of the major objectives of this study was to define the contribution of different leukocyte and endothelial adhesion molecules to the altered leukocyte and platelet interactions elicited by chronic HP infection. For that purpose, monoclonal antibodies against adhesion molecules were used. In addition, the role of selectins was also examined by measuring endothelial cell expression of $\mathrm{P}$-selectin in the stomach and other tissues, using the recently described dual-radiolabeled antibody technique (18). Platelet $\mathrm{P}$-selectin expression and platelet aggregates were measured ex vivo in blood from control and HP-infected animals, and the effects of selectin blockade on aggregate formation were evaluated. Moreover, platelet aggregates were quantified in 
systemic venous blood of HP-infected and control patients, in which platelet activation was also assessed by flow cytometry.

\section{Methods}

Bacterial strains. Fresh isolates of $H$. pylori were cultured from biopsy samples of patients with chronic gastritis, with or without a duodenal ulcer, after previously reported methods (5). In brief, endoscopic biopsy samples were taken from the body and antrum, placed in glass tubes with $0.5 \mathrm{ml}$ of sterile saline, and kept at $4^{\circ} \mathrm{C}$ for less than $1 \mathrm{~h}$. After homogenization, the samples were gently streaked onto brain heart infusion agar plates supplemented with Vitox (Oxoid, Unipath Ltd., Basingstoke, UK), 7\% horse blood, and a mixture of Vancomycin, Trimethoprim, Cefsulodine and Amphotericin B (Oxoid), and incubated for $5-8 \mathrm{~d}$ at $37^{\circ} \mathrm{C}$ under microaerophilic conditions. Samples were also processed for fast red-phenol urea and Fergusson's urea test, and for Gram staining (19). Growing bacteria were identified as HP based on the morphology of colonies, Gram staining, and oxidase, catalase, and urease production. Once grown, isolates were stored at $-70^{\circ} \mathrm{C}$ (Microbank, Pro-Lab Diagnostics, Ontario, Canada) for molecular study and subsequent inoculations.

For molecular characterization of the different strains, colonies were harvested in distilled water, boiled for $10 \mathrm{~min}$, and centrifuged at $13,000 \mathrm{~g}$ for $1 \mathrm{~min}$. A $25-\mu \mathrm{l}$ aliquot of the supernatant was used as the target DNA in amplification assays. The oligonucleotide primers F1 (5'-GAT AAC AGG CAA GCT TTT GAG G-3') and B1 (5'-CTG CAA AAG ATT GTT TGG CAG A- $3^{\prime}$ ) from the HP cagA gene, and V1 (5'-ATT TTA CCT TTT TAC ACA TTC TAG-3') and V2 (5'-AGA AGC CCT GAG ACC G-3') from the HP vacA gene were used to amplify a 348-bp and a 396-bp DNA fragment, respectively. All PCR mixtures contained $50 \mathrm{mM} \mathrm{KCl}, 20 \mathrm{mM}$ Tris- $\mathrm{HCl}, 2.5 \mathrm{mM}$ $\mathrm{MgCl}_{2}, 0.2 \mathrm{mM}$ of each deoxynucleotide, $0.5 \mathrm{mM}$ of each oligonucleotide primer, and $0.5 \mathrm{U}$ of Taq polymerase (Boehringer GmbH, Mannheim, Germany). Amplifications were performed on a PCR system 9600 thermocycler (Perkin-Elmer Corp., Norwalk, CT) with the following cycling profiles: $94^{\circ} \mathrm{C}$ for $1 \mathrm{~min}, 55^{\circ} \mathrm{C}$ for $1 \mathrm{~min}$, and $72^{\circ} \mathrm{C}$ for $1 \mathrm{~min}$ for 35 cycles, and extension at $72^{\circ} \mathrm{C}$ for $5 \mathrm{~min}$. The amplified PCR products were analyzed by agarose gel electrophoresis, stained with ethidium bromide, and examined under UV light. Negative (distilled water and Escherichia coli ATCC 35218 DNA) and positive (NCTC 11637 HP strain) controls were included in each experiment (5).

To ascertain which of the strains expressed the vacuolating cytotoxin encoded by the $v a c A$ gene, cytotoxicity assays on HeLa cells were performed using supernatant proteins from HP concentrated with a ultrafiltration membrane. Vacuolization was assessed by light microscopy and defined as positive (Tox +$)$ when it occurred in more than $50 \%$ cells (6).

Animal model of $H$. pylori infection. $\mathrm{CD}_{1}$ mice of both sexes weighing 25-35 g were obtained from the animal facility of the University of Barcelona, and were housed with a 12-h light dark cycle. Animals had free access to tap water and food, but were not allowed to eat for $24 \mathrm{~h}$ before each of three treatments, which consisted in oral gavage with different fresh isolates of HP, according to the methods described by Marchetti et al. (15). In brief, after an overnight fasting, mice were given $0.25 \mathrm{ml}$ of a solution of $0.2 \mathrm{M} \mathrm{NaHCO}_{3}$ orally through a sterile gavage needle to neutralize acidity. After the bicarbonate treatment, $10^{9} \mathrm{CFUs}$ of each strain in $0.15 \mathrm{ml}$ of sterile saline were administered to each animal through the same route. The same treatment was repeated after 3 and $5 \mathrm{~d}$. Control groups received the same amount of saline alone or a suspension of $10^{9}$ CFUs of E. coli ATCC 35218 after the bicarbonate treatment. Infection in a given mouse was assessed by means of histology, urease test, gram staining and/or culture of gastric samples obtained at the end of the experiments. Microbiological processing of mice gastric samples was identical to that described above for human biopsies.

Histology. At the end of the experiments, mice were killed by an overdose of anesthesia, and approximately one-fifth of the gastric tissue, including oxyntic and fundic mucosa, was cut off, fixed in $4 \%$ buffered formalin, and embedded in paraffin; sections $(5-7 \mathrm{~mm})$ were stained with hematoxylin and eosin after standard procedures. Gastritis was graded from 1-5, following the classification described by Bayerdörffer et al. (9). Infiltration of neutrophils was also graded on a scale of $1-5$, according to the same classification. Each stain was blindly examined by two pathologists, with an interobserver variability of $4 \%$. Intraobserver variability, determined to be $3 \%$, was assessed by reexamining $20 \%$ of random samples.

Monoclonal antibodies. The mAbs used for the assessment of the role of adhesion molecules in the mouse model of HP infection were as follows: RB40.34, a rat IgG1 directed against mouse P-selectin (20); MEL-14, a rat IgG1 directed against mouse L-selectin (21); LAM1-116, a mouse IgG2a directed against mouse L-selectin (22); $\mathrm{UZ4}$, a rat IgM directed against mouse E-selectin (23); M1/70, a rat IgG2a directed against mouse CD11b (24); and YN-1, a rat IgG2b directed against mouse ICAM-1 (25). In some experiments, P-23, a nonbinding murine IgG1 directed against human P-selectin (26) was used as a control mAb. MEL-14 and LAM1-116 were generously provided by Dr. P. Engel (Duke Medical Center, Durham, NC). UZ4 was generously supplied by Dr. R. Hallmann (Institut für Experimentelle Medizin, Erlangen-Nürnberg, Germany), P-23 was produced and purified by protein A-G chromatography (Pharmacia-Upjohn Laboratories, Kalamazoo, MI), and $\mathrm{YN}-1$ was produced at Bayer Laboratories (New Haven, CT). The remaining mAbs were purchased from Pharmingen (San Diego, CA).

For human platelet flow cytometry, the following mAbs, purchased from Immunotech (Marseille, France) were used: phycoerythrin (PE)-conjugated $\mathrm{P} 2$, a mouse $\mathrm{IgG} 1_{\mathrm{k}}$ directed against human GPIIb-IIIa (CD41a), and FITC-labeled CLB-Thromb/6, a mouse IgG1 directed against human P-selectin. As a negative control, 679.1Mc7, a mouse FITC-labeled IgG1 was used.

Intravital microscopy. Mice were anesthetized with subcutaneous ketamine $(150 \mathrm{mg} / \mathrm{kg}$; Ketalar, Parke-Davies Inc., Morris Klein, NJ) and xylazine $(7.5 \mathrm{mg} / \mathrm{kg}$; Sigma Chemical Co., St. Louis, MO), and the left carotid artery was cannulated with PE-10 tubing (Portex Ltd., Hythe, United Kingdom) to monitor continuously blood pressure and to administer drugs and mAbs. Throughout the experiments, rectal temperature was monitored using an electrothermometer, and was maintained between 36.5 and $37.5^{\circ} \mathrm{C}$ with an infrared heat lamp. A midline abdominal incision was made, and the stomach was carefully externalized, opened along the greater curvature, and the gastric contents were gently removed with a sterile swab. Mice were positioned on a $20 \times 30 \mathrm{~cm}$ plexiglas board in a manner that allowed the glandular portion of the stomach to be placed over a glass slide covering a $3.5 \times 3.5 \mathrm{~cm}$ hole centered in the plexiglas. The board was mounted onto the stage of an inverted microscope (Diaphot-300; Nikon, Tokyo, Japan) with a $\times 40$ objective lens and a $\times 10$ eyepiece to observe the gastric microcirculation. The fluorescent dye acridine orange (200 $\mu \mathrm{g} / \mathrm{ml}$; Sigma Chemical Co.) was administered intraarterially to stain leukocytes and platelets (27). The dye was dissolved in sterile saline and filtered through a $0.22-\mu \mathrm{m}$ filter (Millipore Corp., Molsheim, France). Fluorescence (excitation wavelength, 420-490 $\mathrm{nm}$; emission wavelength, $520 \mathrm{~nm}$ ) was detected using a CCD camera model XC-77 (Hamamatsu Photonics, Hamamatsu City, Japan) and a C2400-60 CCD camera control unit with a C2400-68 intensifier head (Hamamatsu Photonics) that was attached to the camera. Images were projected onto a color monitor (Trinitron KX-14CP1; Sony, Tokyo, Japan), and recorded using a video cassette recorder (BRS601MU; JVC, Tokyo, Japan) for off-line analysis. A video date-time generator (Video Timer; KPM Systems, Barcelona, Spain) displayed these parameters on recorded and live images.

Submucosal venules with internal diameters between 15 and 20 $\mu \mathrm{m}$ were selected for observation. Venular diameter was measured on-line using a video caliper (Microcirculation Research Institute, Texas A \& M University). The number of adherent and rolling leukocytes and of circulating platelet aggregates was determined off-line 
during playback of videotaped images. Leukocytes were considered adherent to venular endothelium when stationary for $30 \mathrm{~s}$ or longer, and expressed as number per 100- $\mu \mathrm{m}$ length of venule. Rolling leukocytes were defined as those white blood cells that moved at a velocity less than that of free-flowing leukocytes in the same vessel. The flux of rolling leukocytes was measured as the number of rolling leukocytes that passed a fixed point within a small $(10-\mu \mathrm{m})$ viewing area of the vessel in a 1-min period, using the same area throughout the experiment. Platelet aggregates were seen as large irregularly shaped fluorescent structures with changing morphology, and often included one or more leukocytes that were identified by their characteristic nuclear staining. Their flux was determined in the same manner as that of rolling leukocytes.

After surgery, mice were allowed to stabilize for $15 \mathrm{~min}$ before $0.05 \mathrm{ml}$ of the acridine orange solution was administered. Images from three different venules were recorded for $1 \mathrm{~min}$ each. Because of potential hazards of prolonged fluorescence emission on oxy-radical generation, illumination periods were restricted to $60 \mathrm{~s} \mathrm{(28).}$

Fluorescence intravital microscopy was used to analyze the gastric microcirculation in animals infected with two different strains of HP. Mice inoculated with a $\operatorname{cag} A-$ Tox - strain were studied both at 7 and $14 \mathrm{~d}$ after the end of inoculation (five animals each); six animals infected with a $\operatorname{cag} A+$ Tox + strain were studied between the seventh and the fourteenth day. Control groups included animals inoculated with nontoxigenic Escherichia coli (ATCC 35218) $(n=5)$, and mice receiving only bicarbonate in saline $(n=6)$. In some additional $\operatorname{cag} A+$ Tox + HP-infected animals, after baseline measurements, mAbs directed against L-selectin (LAM1-116, $60 \mu \mathrm{g} / \mathrm{mouse}$; MEL-14, $80 \mu \mathrm{g} /$ mouse), P-selectin (RB40.34, $10 \mu \mathrm{g} /$ mouse), E-selectin (UZ4, $200 \mu \mathrm{g} /$ mouse), ICAM-1 (YN-1, $180 \mu \mathrm{g} / \mathrm{mouse}$ ) or CD11b (M1/70, 60 $\mu \mathrm{g} /$ mouse) were intraarterially given and measurements were repeated after a 5-min period. The concentrations of mAbs used in these studies have been previously demonstrated to have a blocking effect $(21-25,29)$. Administration of LAM1-116 induced a significant decrease on peripheral blood leukocyte counts (from 6,700 \pm 800 to $2,100 \pm 60$ cells $/ \mathrm{ml} ; P=0.001$ ), an effect that was not observed after the administration of any of the remaining mAbs. Platelet counts were unmodified by the mAbs used in these studies.

Endothelial P-selectin expression. The effects of gastric colonization of HP on the expression of endothelial P-selectin were assessed using the dual-radiolabeled $\mathrm{mAb}$ technique (18). In brief, RB40.34, the $\mathrm{mAb}$ directed against mouse P-selectin, was labeled with ${ }^{125} \mathrm{I}$, whereas the nonbinding $\mathrm{mAb}$ P-23 was labeled with ${ }^{131} \mathrm{I}$. In both instances, the iodogen method was used (30). For that purpose, iodogen (1,3,4,6-tetrachloro-3 $\alpha, 6 \alpha$-diphenylglycouril, Sigma Chemical Co.) was dissolved in chloroform at a concentration of $0.5 \mathrm{mg} / \mathrm{ml} ; 250 \mu \mathrm{l}$ of this solution was placed in glass tubes, and chloroform was evaporated under nitrogen. Tubes were kept at $4^{\circ} \mathrm{C}$ until use. For protein iodination, $0.2-0.5 \mathrm{ml}$ of $1 \mathrm{mg} / \mathrm{ml}$ solution of $\mathrm{mAb}$ was incubated in ice with periodical stirring for $12 \mathrm{~min}$ with $1 \mathrm{mCi} / \mathrm{mg}$ protein of the corresponding ${ }^{125} \mathrm{I}$ or ${ }^{131} \mathrm{I}$ iodine. Total volume was brought up to 2.5 $\mathrm{ml}$ by adding PBS. Labeled $\mathrm{mAbs}$ were recovered from the second 2.5-ml fraction collected when making a gel filtration on G-25 Sephadex column (Pharmacia Fine Chemicals, Uppsala, Sweden), and stored in $500-\mu \mathrm{l}$ aliquots at $4^{\circ} \mathrm{C}$ for up to 3 wk before use.

Mice were anesthetized with subcutaneous ketamine $(150 \mathrm{mg} / \mathrm{kg})$ and xylazine $(7.5 \mathrm{mg} / \mathrm{kg})$, and the left carotid artery and femoral vein were cannulated with PE-10 tubing. A mixture of $10 \mu \mathrm{g}$ of ${ }^{125} \mathrm{I}$-Psel $\mathrm{mAb}(\mathrm{RB} 40.34)$ and $2.5 \mu \mathrm{g}$ of ${ }^{131} \mathrm{I}$-nonbinding $\mathrm{mAb}$ (P-23) was administered through the femoral vein catheter. A blood sample was obtained through the carotid artery catheter $5 \mathrm{~min}$ after injection of the $\mathrm{mAb}$ mixture. The animals were then heparinized $(1 \mathrm{mg} / \mathrm{kg}$ sodium heparin) and rapidly exsanguinated by vascular perfusion of sodium bicarbonate buffer via the femoral vein, with simultaneous blood withdrawal via the carotid artery followed by perfusion of sodium bicarbonate buffer via the carotid artery after the inferior vena cava was severed at thoracic level. Entire organs were harvested and weighed. ${ }^{125} \mathrm{I}$ (binding $\mathrm{mAb}$ ) and ${ }^{131} \mathrm{I}$ (nonbinding $\mathrm{mAb}$ ) activities in different organs and in 50- $\mu$ l aliquots of cell-free plasma were counted in a gamma counter (14800 Wizard 3; Wallac, Turku, Finland), with automatic correction for background activity and spillover. The injected activity in each experiment was calculated by counting a 5- $\mu$ l sample of the mixture containing the radiolabeled mAbs. The accumulated activity of each mAb in an organ was expressed as the percentage of the injected activity per gram of tissue. $\mathrm{P}$-selectin expression was calculated by subtracting the accumulated activity of the nonbinding $\mathrm{mAb}\left({ }^{131} \mathrm{I}-\mathrm{P}-23\right)$ from the activity of the binding anti-P-selectin $\mathrm{mAb}\left({ }^{125} \mathrm{I}-\mathrm{RB} 40.34\right)$.

Animals infected with cag $A+\operatorname{Tox}+\operatorname{HP}(n=7)$ and noninfected animals $(n=6)$ were studied. As a positive control, we also studied the expression of P-selectin in four noninfected animals at $4 \mathrm{~h}$ after the intraperitoneal administration of Salmonella abortus equi LPS (5 mg/kg; Sigma Chemical Co.) (31).

Animal platelet activation studies. The presence of circulating activated platelets in HP infection in the mouse was assessed by measuring platelet P-selectin expression in total blood from HP-infected $(n=5)$ and control $(n=5)$ animals by flow cytometry techniques. For that purpose, immunolabeling of platelets with mAbs was performed in whole blood using one-color analysis. In brief, $5 \mu \mathrm{l}$ of whole blood collected in citrate-phosphate-dextrose (citrate final concentration $119 \mathrm{nM}$ ) with PFA (final concentration $0.3 \%$ ) were added to polypropylene tubes preloaded with $50 \mu \mathrm{PBS}$ and incubated with saturating concentrations of FITC-conjugated mAbs (RB40.34 and negative control) in the dark without stirring for 15 min. Samples were then diluted with $1 \mathrm{ml}$ PBS and analyzed with a FACScan flow cytometer (Becton-Dickinson, Mountain View, CA) at an excitation wavelength of $488 \mathrm{~nm}$. Fluorescence and scatter signals were calibrated with $2-\mu \mathrm{m}$ Calibrite beads (Becton-Dickinson). FITC fluorescence was detected with a 530/30-nm band pass filter. Platelets were differentiated from red and white cells by their specific scatter profile (32); histograms were generated from fluorescence data obtained in the logarithmic mode from 5.000 events analyzed in each sample using the LYSYS II 1.1 conversion software (BectonDickinson) in an arithmetic mode (HP 217 computer; Hewlett-Packard, Palo Alto, CA). An analytical marker was set in the green fluorescence channel so that less than $2 \%$ of platelets stained with the negative control showed fluorescence above this level; this marker was used as a threshold to determine the proportion of platelets exhibiting immunofluorescence above this level in samples stained with the anti-P-selectin $\mathrm{mAb}$.

To further study platelet activation in the animal model of HP infection, the presence of circulating platelet aggregates was assessed by measuring the platelet-aggregate ratio according to the $\mathrm{Wu}$ and Hoak method (33) as modified by Wedzicha et al. (34). In brief, blood was taken into a vacutainer tube with EDTA containing $0.15 \%$ paraformaldehyde (PFA); an additional blood sample from the same vein was collected in a similar tube without the addition of PFA. Aggregates present in blood are fixed in the PFA-EDTA mixture, but are broken up by the high concentration of EDTA in the PFA-free tube. The platelet-aggregate ratio is given as the ratio of the platelet count in the PFA-EDTA mixture to that in the EDTA mixture, the counts having been corrected for packed red cell volume. In the absence of platelet aggregates, the platelet-aggregate ratio approaches 1.0. Portal venous blood from $\operatorname{cag} A+$ Tox + HP-infected $(n=5)$ and control animals $(n=3)$ was analyzed. Experiments were performed in triplicate to minimize sampling errors. The effect of $\mathrm{mAbs}$ against $\mathrm{P}-, \mathrm{E}-$ and L-selectin on the presence of portal platelet aggregates was also assessed, using the same doses of mAbs as in the intravital microscopy studies (four animals each).

Human platelet activation studies. The presence of circulating activated platelets in HP-infected humans was assessed using systemic venous blood from HP-positive $(n=5)$ and HP-negative $(n=5)$ patients, and by analyzing the samples using the method of $\mathrm{Wu}$ and Hoak as described above (23). Gastric HP infection was assessed by a commercial urease test (CLOtest; Delta West Ltd., Bently, West Australia) in patients submitted to diagnostic endoscopy because of 
upper gastrointestinal complaints, and was confirmed by a ${ }^{14} \mathrm{C}$-urea breath test (19).

P-selectin expression on platelets in the same population of patients was studied using flow-cytometric techniques. For that purpose, immunolabeling of platelets with mAbs was performed in whole blood using dual-color analysis $(35,36)$. In brief, $5 \mu$ l of whole blood collected in citrate-phosphate-dextrose (citrate final concentration, $119 \mathrm{nM}$ ) with PFA (final concentration, $0.3 \%$ ) were added to polypropylene tubes preloaded with $50 \mu \mathrm{l}$ PBS. Samples for dualcolor analysis were first incubated with saturating concentrations of anti CD41a-PE in the dark, without stirring, for $15 \mathrm{~min}$ at room temperature, followed by the addition of FITC-conjugated mAbs (CLBThromb/6 and negative control) and another incubation for $15 \mathrm{~min}$. Samples were then diluted with $1 \mathrm{ml}$ PBS, and were analyzed with a FACScan ${ }^{\circledR}$ flow cytometer at an excitation wavelength of $488 \mathrm{~nm}$. Fluorescence and scatter signals were calibrated with $2-\mu \mathrm{m}$ Calibrite beads. FITC and PE fluorescence were detected with a 530/30- and 575/26-nm band pass filter, respectively, and overlap in the emission spectra of FITC and PE was corrected. Platelets were differentiated from red and white cells by their specific anti-CD41a-PE membrane immunofluorescence; histograms were generated from fluorescence data obtained in the logarithmic mode from 5.000 events analyzed in each sample using the LYSYS II 1.1 conversion software in an arithmetic mode (HP 217 computer; Hewlett-Packard). An analytical marker was set in the green fluorescence channel so that less than $2 \%$ of platelets stained with the negative control showed fluorescence above this level; this marker was used as a threshold to determine the proportion of platelets exhibiting immunofluorescence above this level in samples stained with the anti-P-selectin mAb.

Statistics. The data were analyzed using standard statistical methods, i.e., analysis of variance with the Scheffé's (post-hoc) tests, and Student's paired or unpaired $t$ test, where appropriate. All values are reported as mean values \pm SEM. Statistical significance was set at $P<$ 0.05 .

All the studies herein reported were conducted according to the standards of the local Ethical Committee of Hospital Clinic i Provincial of Barcelona.

\section{Results}

Bacterial strains and animal model of HP infection. Twelve different HP strains were isolated and characterized. All the $\operatorname{cag} A+\mathrm{HP}$ strains possessed vacuolating activity on HeLa cells (which implies expression of the VacA protein), whereas none of the $\operatorname{cag} A-$ strains induced significant vacuolization. For that reason, two strains, differing with respect to their $\operatorname{cag} A$ gene and Tox status, were selected for this study. The presence of both markers significantly $(P=0.04)$ influenced the ability of these two fresh isolates to colonize effectively the mouse gastric mucosa $(70 \%$ for $\operatorname{cag} A+$ Tox + vs. $33 \%$ for $\operatorname{cag} A-$ Tox - strains) when infection was assessed 2 wk after inoculation. At this time, no gross gastric damage was seen, and the degree of gastritis elicited by HP colonization was moderate (2.5 \pm 0.13$)$ but significantly $(P=0.001)$ higher than that observed in noninfected HP-inoculated animals $(1.7 \pm 0.13), E$. coli-inoculated $(1.3 \pm 0.2)$, or saline-treated controls $(1.1 \pm 0.1)$. The extent of inflammation in HP-infected animals did not seem to be related to the strain used $(2.4 \pm 0.2$ for $c a g A-$ Tox vs. $2.5 \pm 0.1$ for $\operatorname{cag} A+$ Tox $+\mathrm{HP})$. Infiltrating cells were predominantly mononuclear; polymorphonuclear leukocytes in the lamina propria of infected animals were infrequent $(<10 \%$ of infected mice).

Microcirculatory alterations elicited by HP gastric colonization. Whereas animals inoculated with saline or E. coli sustained a low flux of rolling leukocytes in gastric venules, this
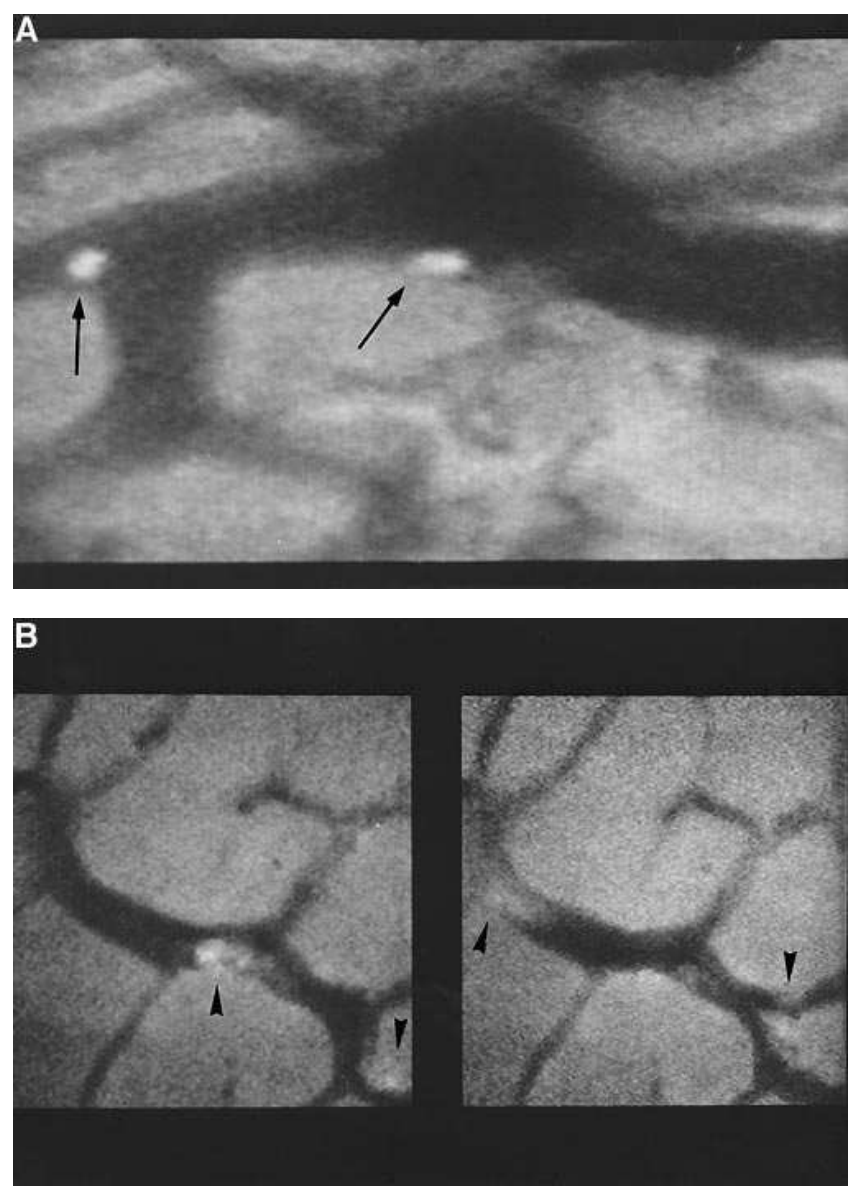

Figure 1. Rolling leukocytes $(A)$ and platelet aggregates $(B)$ circulating within gastric venules from $H$. pylori-infected mice. Rolling leukocytes (arrows) were easily identified after acridine orange labeling as small round structures circulating at a velocity lower than that of free-flowing leukocytes. Platelet aggregates (arrowheads) were seen as large circulating structures with changing morphology, and often included one or more leukocytes identified by their characteristic nuclear staining.

number was significantly increased in HP-infected animals, irrespective of the $\operatorname{cag} A /$ Tox status or the duration of infection (Fig. $1 A$ and Fig. 2). In animals infected with either $\operatorname{cag} A+$ Tox + or $c a g A-$ Tox - HP, the presence of platelet aggregates circulating within the gastric venules proved to be a characteristic feature (Fig. $1 \mathrm{~B}$ and Fig. 2). In contrast, platelet aggregates were never observed in saline-inoculated animals, and only in one out of five mice having received $E$. coli. In neither control nor infected animals were adherent leukocytes observed.

Circulating aggregates seemed to be fundamentally formed by platelets, but leukocytes were often identified within them. To confirm the nature of these aggregates, portal and peripheral blood from infected and control animals was obtained, and extensions were stained with May-Grünwald Giemsa. Fig. 3 is a representative image of portal blood extensions from HPinfected animals, in which leukocyte-platelet as well as platelet-platelet aggregates were identified. Although homotypic platelet aggregates were also present on systemic venous blood from the same animals, leukocyte-platelet interactions were less frequently observed in these samples. Only occasion- 


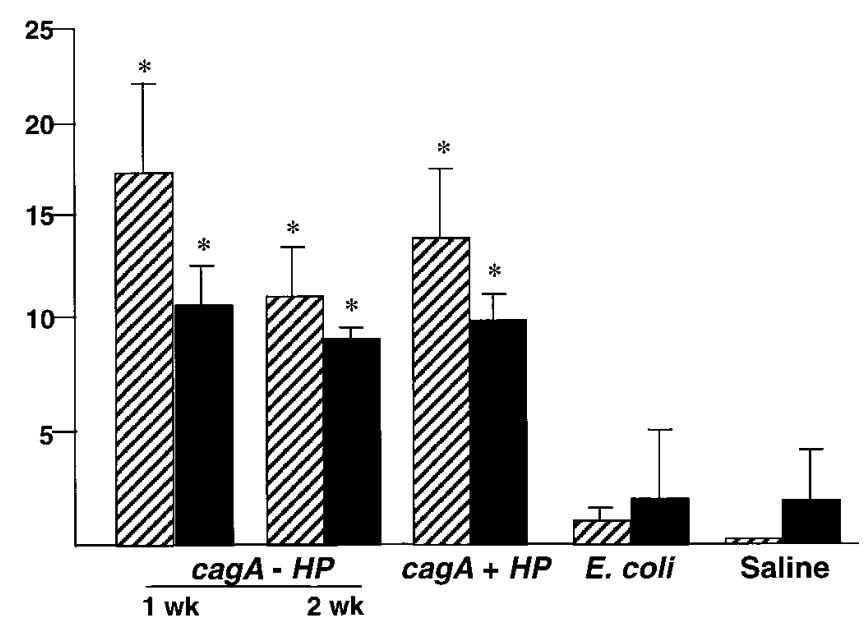

Figure 2. Flux of rolling leukocytes and platelet aggregates in animals inoculated with two different $H$. pylori strains, E. coli, or saline. Both parameters were similar in HP-infected animals, independently of the duration of infection or the Tox/cag $A$ status, but higher than those observed in $E$. coli or saline-treated animals $(* P<0.05)$. Black bars, rolling leukocytes (cells/min); striped bars, platelet aggregates $(n / \mathrm{min})$.

ally were platelet aggregates identified in blood from control animals.

Molecular determinants of leukocyte rolling and aggregate formation. In cag $A+$ Tox + HP-infected mice, both P- and L-selectin blockade resulted in a significant decrease in the number of rolling leukocytes within the gastric microvessels, reaching values similar to those of control animals (Fig. $4 A$ ). This effect contrasts with the lack of effect on this parameter of the administration of blocking mAbs against E-selectin, ICAM-1, or CD11b.

In the same group of animals, treatment with a mAb directed against P-selectin was followed by near complete disappearance of platelet aggregates within the gastric microvessels (Fig. 4 B). In a similar manner, L-selectin blockade resulted in a significant decrement in the flux of these aggregates (Fig. 4 $B)$. E-selectin does not appear to contribute to this phenomenon since administration of a blocking dose of an anti-E-selectin $\mathrm{mAb}$ had no effect on the number of flowing aggregates per minute (Fig. 4 B). As expected, neither anti-ICAM-1 nor anti-CD11b exerted any significant effect in the flux of aggregates.

Endothelial P-selectin expression. Because P-selectin is present both in Weibel-Palade bodies from endothelial cells and $\alpha$-granules of platelets (16), endothelial P-selectin expression was assessed taking advantage of the recently described dual-radiolabeled antibody technique (18). Fig. 5 summarizes the surface expression of endothelial P-selectin in splanchnic (Fig. $5 A$ ) and nonsplanchnic vascular beds (Fig. $5 B$ ) in control and $\operatorname{cag} A+$ Tox + HP-infected animals, as well as in LPSpretreated mice. Infection with HP did not significantly change the expression of endothelial P-selectin in any of the organs studied, including the stomach. Conversely, LPS pretreatment resulted in a 10-fold increase in P-selectin expression in all organs, except for heart and brain (about 25 -fold increase) and kidneys (2.5-fold increase).

Murine platelet activation studies. In mice, $c a g A+$ Tox + HP infection was associated to an increase in the platelet surface expression of the activation marker P-selectin as measured by flow cytometry (Fig. 6). This fact was accompanied by the presence of a large number of circulating platelet aggregates, as reflected by the significantly lower platelet-aggregate ratio in portal blood from infected animals, relative to control mice (Fig. 7). In infected animals, administration of a blocking dose of a mAb against L- or P-selectin (5 min before blood withdrawal) was followed by complete disappearance of platelet aggregates in portal blood, as reflected by normalization of the platelet-aggregate ratio (Fig. 7).

Human platelet activation studies. Since our results in the mouse model clearly indicate that HP infection induces the formation of platelet aggregates, we assessed whether this phenomenon also accompanies HP infection in humans. For that purpose, we analyzed blood samples from patients undergoing upper gastrointestinal endoscopy. Previous history of diabetes

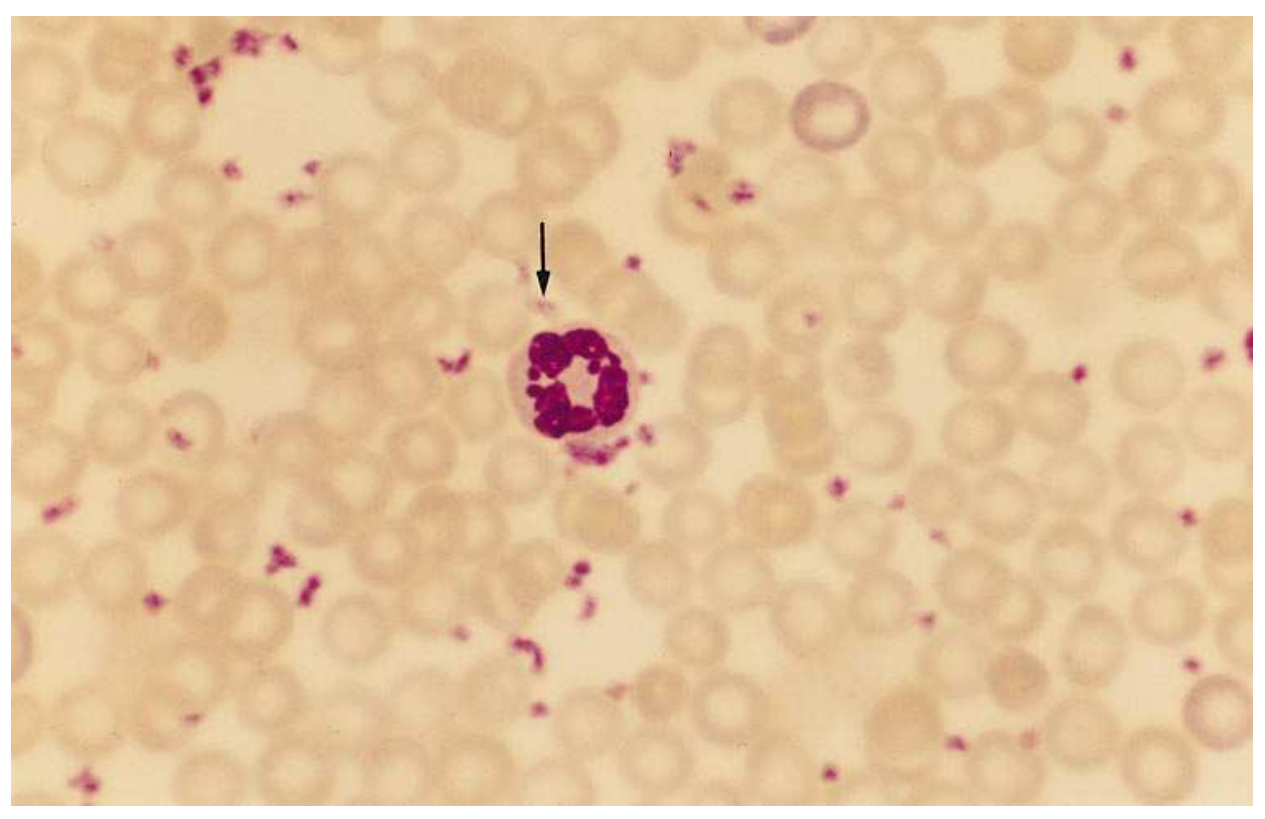

Figure 3. Leucocyte-platelet aggregate observed under clear-field microscopy in a portal blood extension from an HP-infected mice. Some platelets adherent to the leukocyte are completely degranulated (arrow). 
$\mathbf{A}$

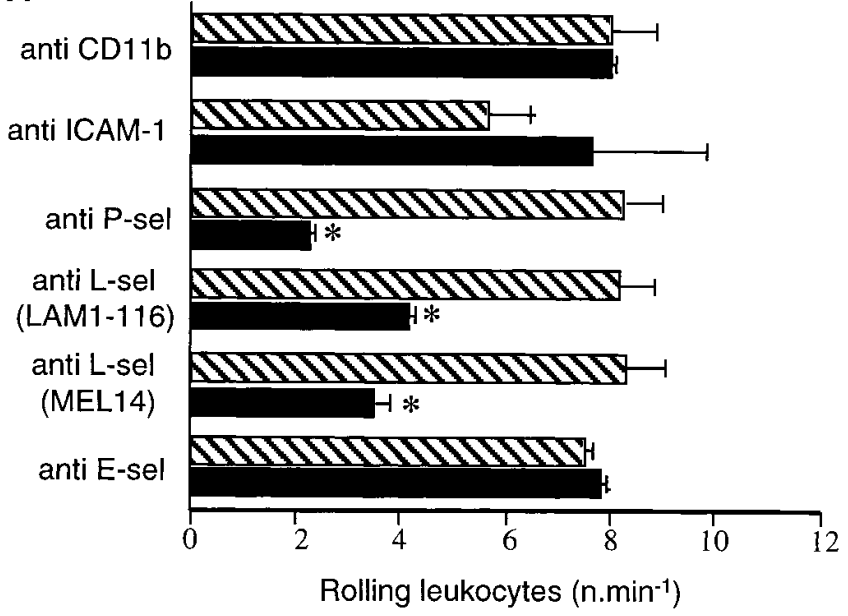

$\mathbf{B}$

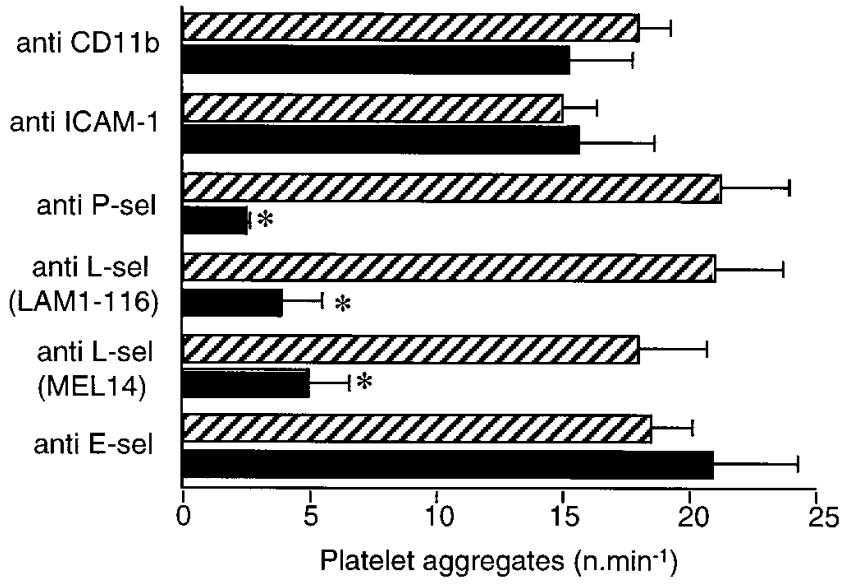

Figure 4. Effects of immunoneutralization of adhesion molecules on the flux of rolling leukocytes $(A)$ and platelet aggregates $(B)$ in the gastric venules in Tox $+c a g A+$ HP-infected animals. Results are expressed as mean values from four animals before and five min after the intravenous administration of a blocking dose of the corresponding $\mathrm{mAb}\left({ }^{*} P<0.01\right)$. Striped bars, before $\mathrm{mAb}$; black bars, after $\mathrm{mAb}$.

$\mathbf{A}$

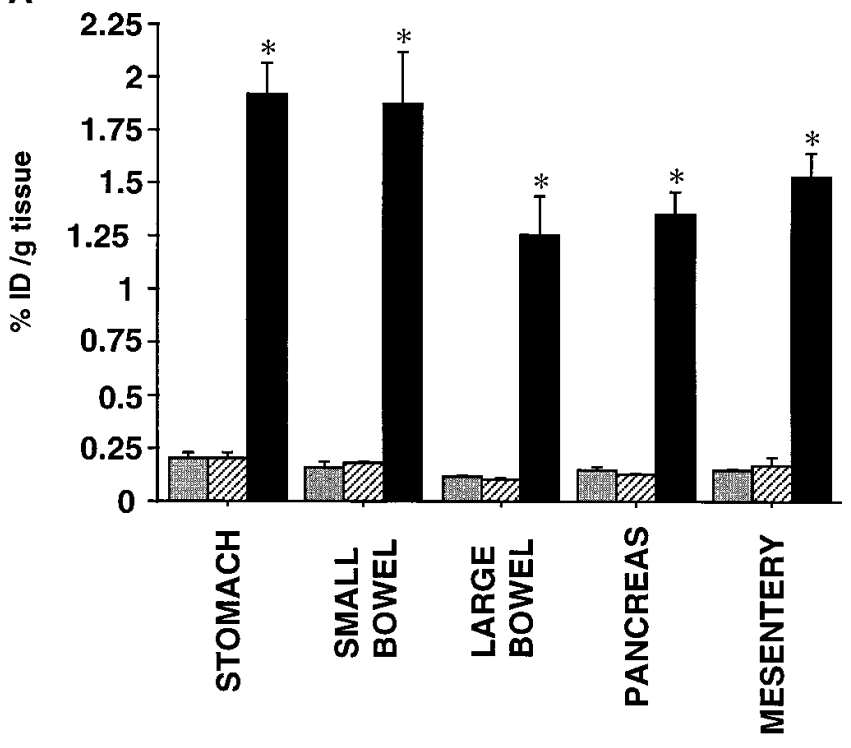

B

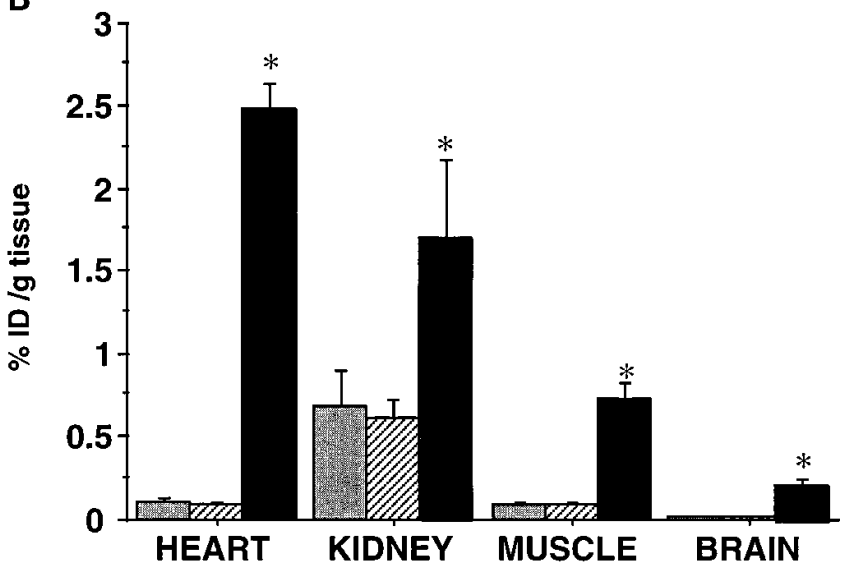

Figure 5. P-selectin expression in endothelium from splanchnic $(A)$ and nonsplanchnic $(B)$ organs in animals infected with Tox $+\operatorname{cag} A+$ HP $(n=7)$ as compared to saline (negative controls; $n=6)$ or LPS mellitus, ischemic heart disease, severe pulmonary obstructive disease, or peripheral arterial disease were excluded in all cases. Five of the patients (three men and two women) had an antral or duodenal ulcer with HP colonization, as demonstrated by CLO test and ${ }^{14} \mathrm{C}$-urea breath test. The remaining five patients (two reflux esophagitis, one esophageal diverticle, one gastric adenocarcinoma, and one normal endoscopic appearance) were all HP-negative (two men and three women). Mean age was similar in HP-positive (64 \pm 3 yr) and HP-negative $(62 \pm 9 \mathrm{yr})$ patients.

Although circulating platelet aggregates were not observed in HP-negative patients (as reflected by an aggregate ratio close to 1.00) all of the five HP-positive cases did have circulating aggregates (Fig. 8). To further assess platelet activation in these patients, surface expression of P-selectin on platelets was monitored in whole blood by flow cytometry. In agreement with the platelet aggregate ratio measurements, blood samples from HP-positive patients exhibited a higher percentage of P-selectin positive platelets than did HP-negative cases (Fig. 9).

\section{Discussion}

During the past few years, there has been a growing body of evidence that implicates the inflammatory response elicited by HP colonization as a critical event in the pathophysiology of gastric ulceration. At the same time, there have been significant advances in our understanding of the basic molecular mechanisms that regulate the trafficking of leukocytes in the microcirculation. These advances have largely resulted from the broad application of monoclonal antibodies to techniques such as flow cytometry and intravital videomicroscopy (37). Because of the absence of suitable animal models of HP infection and the complexity of applying intravital microscopic techniques to solid organs such as the stomach, most of the

pretreated mice (positive controls, $n=4$ ). Results are expressed as $\%$ of total injected dose per gram of tissue $(* P<0.01)$. Shaded bars, control; striped bars, helicobacter; black bars, LPS. 


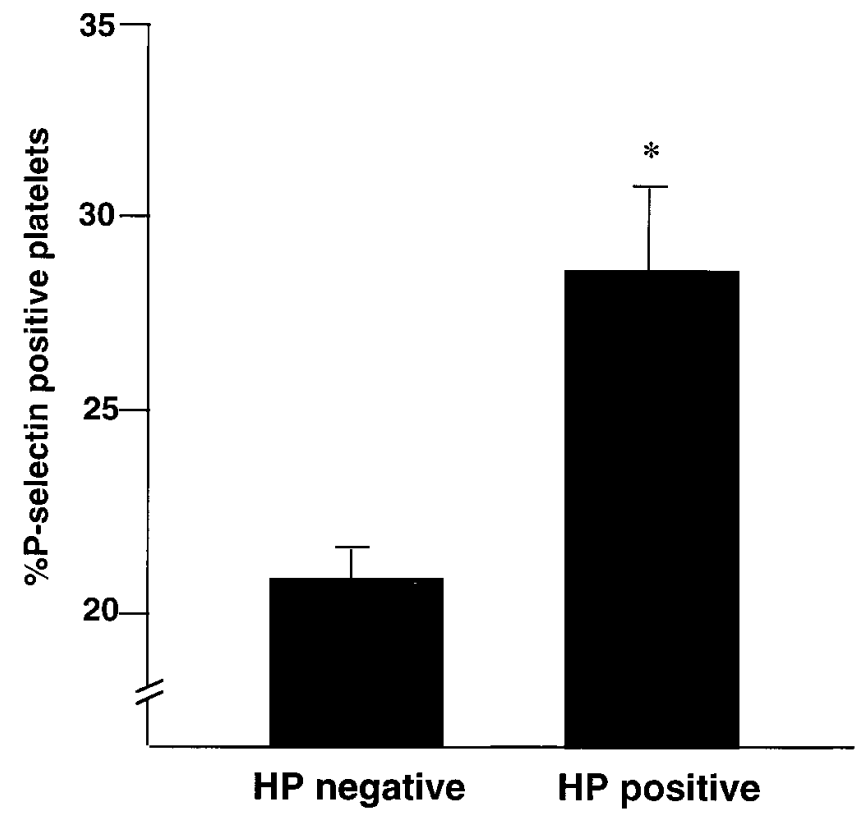

Figure 6. Analysis of platelet $\mathrm{P}$-selectin surface expression in venous blood from HP-infected and control mice. Results are expressed as percentage of platelets labeled with a specific $\mathrm{mAb}$ against $\mathrm{P}$-selectin $(* P<0.05)$.

data related to the mechanisms involved in HP-induced inflammation have been obtained using indirect approaches (1014). In this regard, acute exposure of the mesenteric microcirculation to bacterial filtrates or soluble extracts of HP have provided a large amount of valuable data. It is not clear, however, whether the data obtained from mesenteric venules that are directly exposed to bacterial extracts can be extrapolated to the responses elicited in gastric mucosal microvessels that are exposed to the same bacterial products during a state of chronic infection.

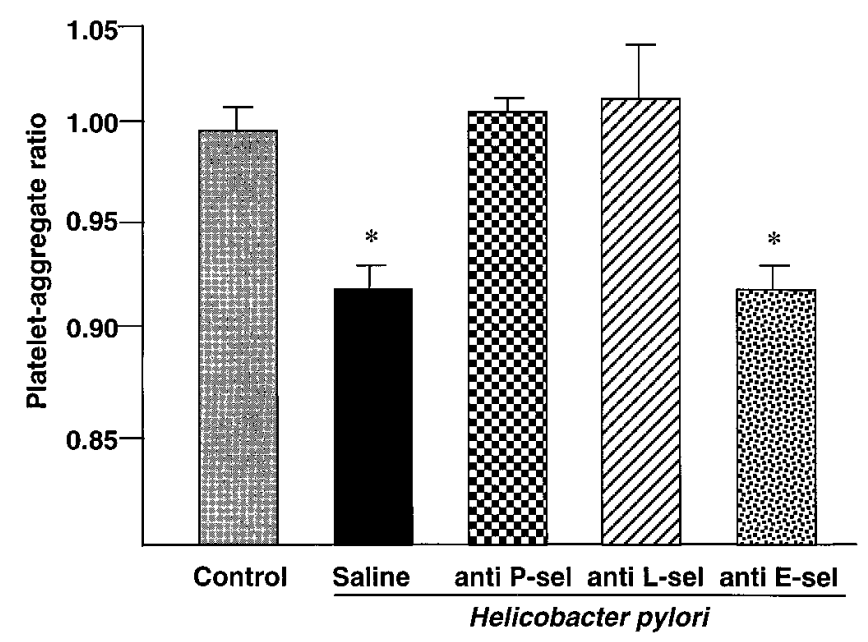

Figure 7. Platelet-aggregate ratio in portal blood from control and Tox + cagA + HP-infected mice. Whereas in infected animals this parameter was decreased, reflecting the presence of platelet aggregates, the ratio was normalized in infected mice receiving a blocking dose of a $\mathrm{mAb}$ against $\mathrm{P}$ - or L-selectin $5 \mathrm{~min}$ before blood sampling (four animals per group; $* P<0.05)$.

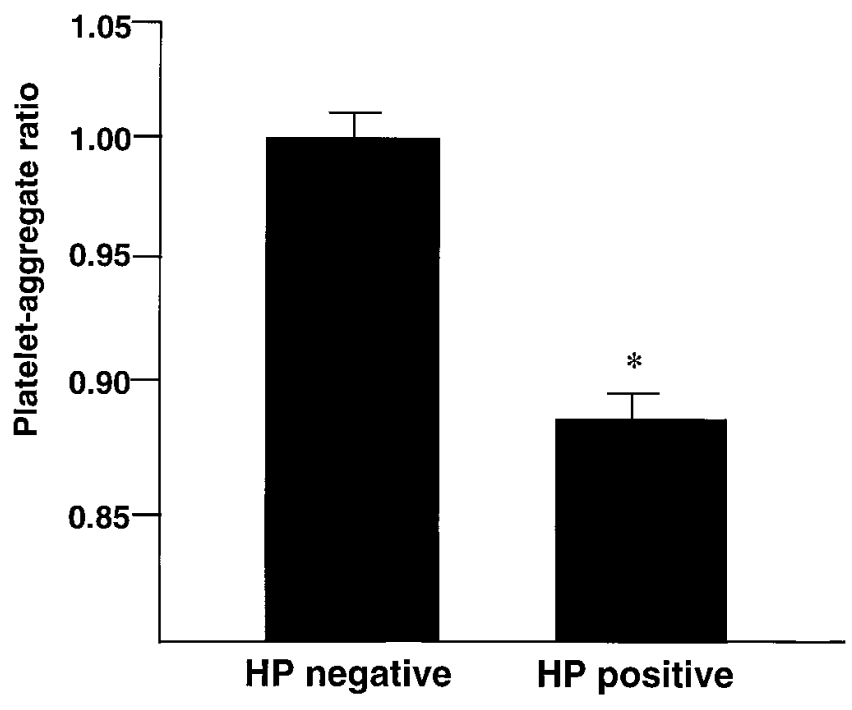

Figure 8. Platelet-aggregate ratio as measured by the $\mathrm{Wu}$ and Hoak method in systemic venous blood from HP- and HP+ dyspeptic patients. Similarly to that occurring in mice, HP positivity was significantly associated to a lower platelet-aggregate ratio, thus reflecting the existence of circulating platelet aggregates $(* P<0.05)$.

The current work was undertaken to characterize the microvascular events elicited by gastric HP colonization in a wellcharacterized mouse model of HP infection $(15,33)$. In our hands, the ability of fresh HP isolates to colonize the mouse gastric mucosa was dependent on bacterial strain, with $\operatorname{cag} A+$ Tox + strains having a twofold rate of colonization, relative to $\operatorname{cag} A-$ Tox - strains. These results are in keeping with previously published data $(15,38)$. The inflammatory response elic-

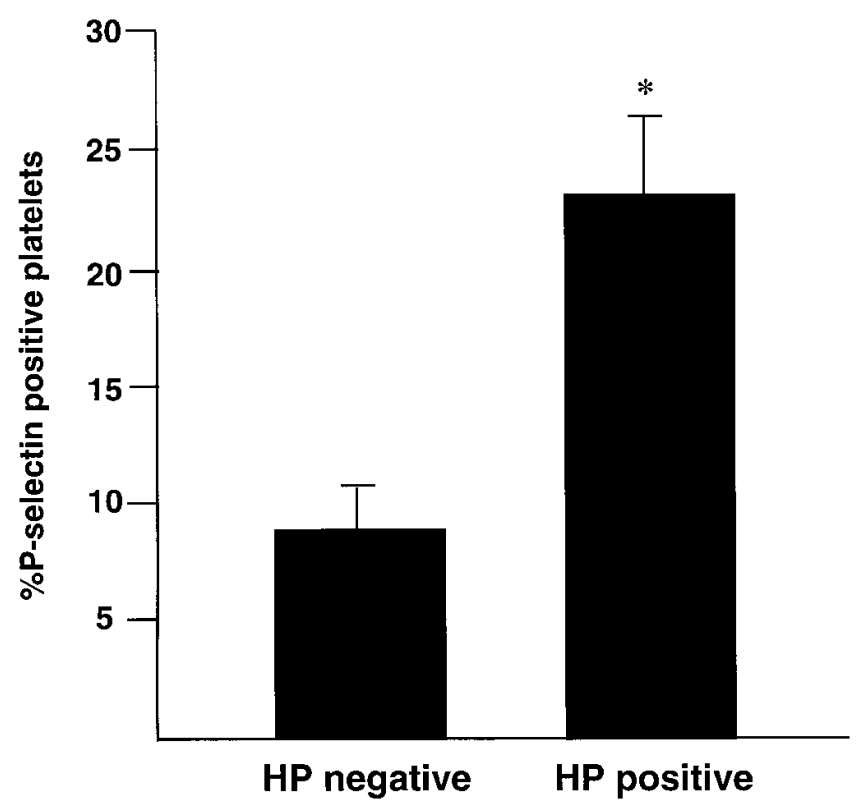

Figure 9. Analysis of platelet P-selectin surface expression in systemic venous blood from $\mathrm{HP}-$ and $\mathrm{HP}+$ patients. Results are expressed as percentage of platelets labeled with a specific $\mathrm{mAb}$ against P-selectin $(* P<0.05)$. 
ited by such colonization was characterized by the presence of a diffuse mononuclear cell infiltrate, a finding also coincident with previous published work $(15,38)$. The similar degree of inflammation observed in animals infected with $\operatorname{cag} A+$ and $\operatorname{cag} A-$ strains supports the hypothesis that other factors distinct from the CagA molecule are responsible for eliciting inflammation in the gastric mucosa (38). Our results also confirm the existence of marked differences between the human and mouse inflammatory response, since infiltrating cells are mainly of the mononuclear type in mice, whereas polymorphonuclear leukocytes predominate in active gastritis in man (9).

Irrespective of the duration of infection or the $\operatorname{cag} A /$ Tox status, HP infection caused a significant increase in the flux of rolling leukocytes in gastric submucosal venules. This finding, not previously reported, is in agreement with an increased leukocyte adhesion in mesenteric $(12,14)$ and submucosal gastric (39) venules after superfusion of HP extracts. The enhanced leukocyte rolling is not likely due to differences in shear stress between control and infected animals since mean arterial blood pressure, velocity of free-flowing leukocytes, and gastric mucosal blood flow measured by the hydrogen gas clearance technique were not decreased (data not shown) in infected mice. In addition, a possible effect of acridine orange, the fluorescent dye used to stain leukocytes, in leukocyte rolling has been ruled out in previous studies (27).

Leukocyte-platelet aggregates have been reported to form in clinical conditions such as respiratory distress, myocardial infarction, or hemodialysis $(17,40,41)$, and in certain experimental models (42), including superfusion of HP extracts on rat mesenteric (14) and gastric (39) venules. In this paper, we demonstrate that the formation of platelet aggregates is the most prominent feature in the gastric microvasculature of mice infected with HP. This effect seems to be highly specific for HP infection, since animals challenged with other bacteria exhibited few aggregates (only one out of five mice), that were never observed in the gastric microvasculature of saline-control animals. In the animal model of HP infection, the nature of aggregates is likely mixed, with both homogeneous (platelet-platelet) and heterogeneous (leukocyte-platelet) structures coexisting. Several indirect evidences support this contention: it has been previously shown that superfusion of the mesentery with HP extracts induces the formation of leukocyte-platelet aggregates, which are easily identified under clear-field microscopy (14); the aspect of leukocyte-platelet aggregates elicited by endotoxemia on the mesenteric circulation under fluorescence microscopy is similar to that of aggregates present in gastric microvessels of HP infected mice (personal observations); L-selectin blockade (LAM 1-116 and MEL-14) markedly decreases the number of circulating aggregates, this fact implying a direct or indirect participation of leukocytes on their formation; finally, in portal blood extensions from HP-infected animals both leukocyte-platelet and platelet-platelet aggregates were clearly identified. Only the latter, however, were consistently seen in peripheral blood from infected animals. This fact is probably related to the filtering effect of pulmonary circulation or to the dynamics of leukocyteplatelet interactions (40).

In this study, we provide evidence that both leukocyte rolling and the formation of platelet aggregates are dependent on $\mathrm{P}$ - and L-selectin, since blocking $\mathrm{mAbs}$ directed against either of these adhesion molecules resulted in a pronounced reduction in the flux of rolling leukocytes, and in the presence of ag- gregates within gastric microvessels (intravital microscopy studies) and portal blood (normalization of platelet-aggregate ratio) in HP-infected animals. Both molecules have been implicated in leukocyte rolling in a variety of conditions (21) in which participation of P-selectin has been supposed to be a consequence of an enhanced expression of this adhesion molecule by the endothelium. A platelet pathway operating through P-selectin, however, has recently been shown to mediate leukocyte rolling on high endothelial venules in vivo (43). The inhibitory effect of an anti-P-selectin $\mathrm{mAb}$ on leukocyte rolling may hence result from an action on P-selectin expressed either on platelets, endothelial cells, or both. To ascertain whether endothelial P-selectin expression was enhanced in animals infected with HP, the dual-radiolabeled antibody technique was used. We found that HP-infected animals did not exhibit an increased expression of P-selectin in any vascular bed, when compared to control mice. In contrast, platelet P-selectin expression in HP-infected mice was significantly enhanced with respect to that of control animals. The presence of platelet aggregates in portal blood from HP-infected animals and the abrogation of aggregate formation by treatment with an anti$\mathrm{P}$-selectin $\mathrm{mAb}$ add further support to the contention that $\mathrm{HP}$ infection activates platelets. Although the absolute difference in platelet-aggregate ratio between infected and control animals was low, it reflects a large number of circulating aggregates since platelet counts in mice usually exceed $10^{6} / \mathrm{ml}$. The lack of differences in endothelial P-selectin expression between infected and control animals argues against a role for this endothelial molecule in the increased leukocyte rolling observed in HP infection, suggesting that a platelet P-selectin operating pathway is involved in this phenomenon. The existence of constitutive endothelial P-selectin expression in the gastric vascular network, however, although at a very low level, does not allow to definitely rule out its contribution to leukocyte rolling in this setting.

Involvement of P-selectin in the formation of leukocyteplatelet aggregates could be anticipated, since other authors previously demonstrated a major role for this adhesion molecule in such interactions $(14,40,41)$. A mechanism accounting for the effects of L-selectin blockade on aggregate formation, however, is not straightforward. Leukopenia could be responsible, at least in part, for the effect of LAM 1-116, but not for the effect of MEL-14, on aggregate formation. L-selectin has been proposed as a ligand for P-selectin (44-46), but some authors disagree (47); others have suggested that both molecules would be necessary, but neither sufficient to mediate adhesion by interacting with distinct counterreceptors (48). Alternatively, the possibility exists that platelet activation in the setting of HP infection results from leukocyte-dependent mechanisms, which may be abrogated to some extent by L-selectin blockade (49).

Because platelet aggregation was a marked and reproducible phenomenon in the experimental model of HP infection, we assessed whether platelet activation and aggregation is also present in systemic venous blood from HP-infected and control patients. Using two different techniques (flow cytometry and the $\mathrm{Wu}$ and Hoak method), we were able to demonstrate that platelet activation does indeed occur in human HP infection. Moreover, the degree of platelet activation seems to be similar to that reported in other clinical conditions in which platelet-leukocyte aggregation is thought to play a pathophysiological role $(17,40-43,50)$. 
The significance of platelet-leukocyte aggregate formation in HP infection is unknown, but the interaction between both cell types is considered to be of pathophysiological relevance in situations such as septic shock, thrombosis, and atherosclerosis $(42,50)$. There is evidence showing that leukocytes can activate platelets $(49,51)$, and that activated platelets can increase the production of superoxide anion $(52,53)$ or PAF $(54)$ by leukocytes. Moreover, neutrophils use platelet-derived arachidonate to increase leukotriene and thromboxane synthesis through P-selectin interactions (55). Since PAF, leukotrienes, thromboxane, and other leukocyte and platelet activation products are known to accumulate in the gastric mucosa of HP-infected patients (56), it appears reasonable to postulate that leukocyte-platelet aggregates contribute to the pathogenesis of HP-associated gastric damage. In addition, platelet activation elicited by HP infection might be involved in the proposed association between HP seropositivity and coronary heart disease $(2-4)$.

In summary, our study provides the first demonstration that HP infection in mice increases the flux of rolling leukocytes and elicits the formation of platelet aggregates in the gastric microvasculature. Platelet P-selectin expression plays a major role in the formation of these aggregates, but leukocyte L-selectin is also involved. In contrast, endothelial P-selectin expression is not enhanced as a consequence of HP gastric colonization. Furthermore, our results provide the first evidence that platelet aggregates are induced in HP infection in humans. Activation of human platelets elicited by HP colonization of the stomach represents a potentially important component of vascular contribution to the pathophysiology of HP-associated diseases.

\section{Acknowledgments}

This work was supported by grants from Schering-Plough España, and from the Comisión Interministerial de Ciencia y Techologia (PETRI 95-0048-OP). Julià Gómez was a recipient of a grant from Hospital Clínic i Provincial de Barcelona. Dr. Neil Granger is supported by a grant from the National Heart, Lung, and Blood Institute (HL26441).

\section{References}

1. The Eurogast study group. 1994. Epidemiology of, and risk factors for Helicobacter pylori infection among 3194 asymptomatic subjects in 17 populations. Gut. 34:1672-1676.

2. Mendall, M.A., P.M. Goggin, N. Molineaux, J. Levy, T. Toosy, D. Strachan, A.J. Camm, and T.C. Northfield. 1994. Relation of Helicobacter pylori infection and coronary heart disease. Br. Heart J. 71:437-439.

3. Patel, P., D. Carrington, D.P. Strachan, E. Leatham, P. Goggin, T.C. Northfield, and M.A. Mendall. 1994. Fibrinogen, a link between chronic infection and coronary heart disease. Lancet. 343:1634-1635.

4. Whincup, P.H., M.A. Mendall, I.J. Perry, D.P. Strachan, and M. Walker. 1996. Prospective relations between Helicobacter pylori infection, coronary heart disease, and stroke in middle aged men. Heart (Lond.). 75:568-572.

5. Xiang, Z., S. Censini, P.F. Bayelli, J.L. Telford, N. Figura, R. Rappuoli, and A. Covacci. 1995. Analysis of expression of CagA and VacA virulence factors in 43 strains of Helicobacter pylori reveals that clinical isolates can be divided into two major types and that CagA is not necessary for expression of the vacuolating cytotoxin. Infect. Immun. 63:94-98.

6. Cover, T.L., W. Puryear, G.J. Pérez-Pérez, and M.J. Blaser. 1991. Effect of urease on HeLa cell vacuolation induced by Helicobacter pylori cytotoxin. Infect. Immun. 59:1264-1270.

7. Crowe, S.E., L. Alvarez, M. Dytoc, R.H. Hunt, M. Muller, P. Sherman, J. Patel, Y. Jin, and P.B. Ernst. 1995. Expression of interleukin 8 and CD54 by human gastric epithelium after Helicobacter pylori infection in vitro. Gastroenterology. 108:65-74.

8. Kozol, R., A. Domanowski, A. Jaszewski, R. Czanko, B. McCurdy, M.
Prasad, B. Fromm, and R. Calzada. 1991. Neutrophil chemotaxis in gastric mucosa: a signal-to-response comparison. Dig. Dis. Sci. 36:1277-1280.

9. Bayerdorffer, E., N. Lehn, R. Hatz, G.A. Mannes, H. Oertel, T. Sauerbruch, and M. Stolte. 1992. Difference in expression of Helicobacter pylori gastritis in antrum and body. Gastroenterology. 102:1575-1582.

10. Mai, U.E.H., G.I. Pérez-Pérez, L.M. Wahl, S.M. Wahl, M.J. Blaser, and P.D. Smith. 1991. Soluble surface proteins from Helicobacter pylori activate monocytes/macrophages by lipopolysaccharide-independent mechanism. $J$. Clin. Invest. 87:894-900.

11. Mai, U.E.H., G.I. Pérez-Pérez, J.B. Allen, S.M. Wahl, M.J. Blaser, and P.D. Smith. 1992. Surface proteins from Helicobacter pylori exhibit chemotactic activity for human leukocytes and are present in gastric mucosa. J. Exp. Med. 175:517-525.

12. Yoshida, N., D.N. Granger, D.J. Evans, D.G. Evans, D.Y. Graham, D.C. Anderson, R. Wolf, and P.R. Kvietys. 1993. Mechanisms involved in Helicobacter pylori-induced inflammation. Gastroenterology. 105:1431-1440.

13. Enders, G., W. Brooks, N. VonJan, N. Lehn, E.Bayerdorffer, and R. Hatz. 1995. Expression of adhesion molecules on human granulocytes after stimulation with Helicobacter pylori membrane proteins: comparison with membrane proteins from other bacteria. Infect. Immun. 63:2473-2477.

14. Kurose, I., D.N. Granger, D.J. Evans, D.G. Evans, D.Y. Graham, M Miyasaka, D.C. Anderson, R. Wolf, G. Cepinskas, and P.R. Kvietys. 1994. Helicobacter pylori-induced microvascular protein leakage in rats: role of neutrophils, mast cells, and platelets. Gastroenterology. 107:70-79.

15. Marchetti, M., B. Aricò, D. Burroni, N. Figura, R. Rappuoli, and P. Ghiara. 1995. Development of a mouse model of Helicobacter pylori infection that mimics human disease. Science (Wash. DC). 267:1655-1658.

16. Tedder, T.F., D.A. Steeber, A. Chen, and P. Engel. 1995. The selectins: vascular adhesion molecules. FASEB J. 9:866-873.

17. Parmentier, S., L. McGregor, B. Catimel, L.L.K. Leung, and J.L. McGregor. 1991. Inhibition of platelet function by a monoclonal antibody (LYP20) directed against a granule membrane protein (GMP-140/PADGEM). Blood. 77:1734-1739.

18. Panés, J., M.A. Perry, D.C. Anderson, A. Manning, B. Leone, G. Cepin skas, C.L. Rosenbloom, M. Miyasaka, P.R. Kvietys, and D.N. Granger. 1995. Regional differences in constitutive and induced ICAM-1 expression in vivo. Am. J. Physiol. 269:H1955-1964.

19. Cutler, A.F. 1996. Testing for Helicobacter pylori in clinical practice. Am. J. Med. 100:35s-39s.

20. Bosse, R., and D. Vestweber. 1994. Only simultaneous blocking of the L- and P-selectin completely inhibits neutrophil migration into mouse peritoneum. Eur. J. Immunol. 24:3019-3024.

21. Ley, K., D.C. Bullard, M.L. Arbones, R. Bosse, D. Vestweber, T.F. Tedder, and A.L. Beaudet. 1995. Sequential contribution of L- and P-selectin to leukocyte rolling in vivo. J. Exp. Med. 181:669-675.

22. Tedder, T.F., D.A. Steeber, and P. Pizcueta. 1995. L-selectin-deficient mice have impaired leukocyte recruitment into inflammatory sites. J. Exp. Med. 181:2259-2264.

23. Austrup, F., D. Vestweber, E. Borges, M. Löjning, R. Bräuer, U. Herz, H. Renz, R. Hallmann, A. Scheffold, A. Radbruch, and A. Hamann. 1997. Pand E-selectin mediate recruitment of T-helper-1 but not T-helper-2 cells into inflamed tissues. Nature (Lond.). 385:81-83.

24. Nolte, D., R. Hecht, P. Schmid, A. Botzlar, M.D. Menger, C. Neumueller, F. Sinowatz, D. Vestweber, and K. Messmer. 1994. Role of Mac-1 and ICAM-1 in ischemia reperfusion injury in a microcirculation model of BALB/C mice. Am. J. Physiol. 267:H1320-H1328.

25. Henninger, D.D., J. Panés, J. Russell, M. Gerritsen, D.C. Anderson, and D.N. Granger. 1997. Cytokine-induced VCAM-1 and ICAM-1 expression in different organs of the mouse. J. Immunol. 158:1825-1832.

26. Ma, L., L. Raycroft, D. Asa, D.C. Anderson, and J.G. Geng. 1994. A sialoglycoprotein from human leukocytes functions as a ligand for P-selectin. $J$. Biol. Chem. 269:27739-27746.

27. Janssen, G.H.G.W., G.J. Tangelder, M.G.A. Oude Egbrink, and S. Reneman. 1994. Spontaneous leukocyte rolling in venules in untraumatized skin of conscious and anesthetized animals. Am. J. Physiol. 267:H1199-H1204.

28. Reed, M.W.R., and F.N. Miller. 1988. Importance of light dose in fluorescent microscopy. Microvasc. Res. 36:104-107.

29. Eppihimer, M.J., B. Wolitzky, D.C. Anderson, M.A. Labow, and D.N Granger. 1996. Heterogeneity of expression of E- and P-selectins in vivo. Circ. Res. 79:560-569.

30. Fraker, P.J., and J.C. Speck. 1978. Protein and cell membrane iodination with a sparingly soluble chloramine. Biochem. Biophys. Res. Commun. 80:849856.

31. Auchampach, J.A., M.G. Oliver, D.C. Anderson, and A.M. Manning. 1994. Cloning, sequence comparison and in vivo expression of the gene encoding rat P-selectin. Gene (Amsterdam). 145:251-255.

32. Wall, J.E., M. Buijs-Wilts, J.T. Arnold, W. Wang, M.H. White, L.K. Jennings, and C.W. Jackson. 1995. A flow cytometric assay using mepacrine for study of uptake and release of platelet dense granule contents. Br. J. Haematol. 89:380-385.

33. Wu, K.K., and J.C. Hoak. 1974. A new method for the quantitative detection of platelet aggregates in patients with arterial insufficiency. Lancet. ii: 
924-926.

34. Wedzicha, J.A., D. Syndercombe-Court, and K.C. Tan. 1991. Increased platelet aggregate formation in patients with chronic airflow obstruction and hypoxaemia. Thorax. 46:504-507.

35. Shattil, S.J., M. Cunningham, and J.A. Hoxie. 1987. Detection of activated platelets in whole blood using activation-dependent monoclonal antibodies and flow-cytometry. Blood. 70:307-315.

36. Scharf, R.E., A. Tomer, U.M. Marzec, P.S. Teirstein, Z.M. Ruggeri, and L.A. Harker. 1992. Activation of platelets in blood perfusing angioplasty-damaged coronary arteries-flow cytometric detection. Arterioscler. Thromb. 12: 1475-1487.

37. Carlos, T.M., and J.M. Harlan. 1994. Leukocyte-endothelial adhesion molecules. Blood. 84:2068-2101.

38. Ghiara, P., M. Marchetti, M.J. Blaser, M.K.R. Tummuru, T.L. Cover, E.D. Segal, L.S. Tompkins, and R. Rappuoli. 1995. Role of the Helicobacter pylori virulence factors vacuolating cytotoxin, CagA, and urease in a mouse model of disease. Infect. Immun. 63:4154-4160.

39. Kalia, N., D. Morton, S. Jacob, N.J. Brown, M.W. R. Reed, and K.D. Bardhan. 1996. The role of platelets and mast cells in Helicobacter pyloriinduced changes in rat gastric mucosal microcirculation in vivo. Gastroenterology. 110:148a (Abstr.)

40. Rinder, H.M., J.L. Bonan, C.S. Rinder, K.A. Ault, and B.R. Smith. 1991. Dynamics of leukocyte-platelet adhesion in whole blood. Blood. 78:17301737.

41. Stuard, S., M.P. Carreno, J.L. Poignet, A. Albertazzi, and N. HaeffnerCavaillon. 1995. A major role for CD62P/CD15s interaction in leukocyte margination during hemodialysis. Kidney Int. 48:93-102.

42. Frenette, P.S., R.C. Johnson, R. Hynes, and D.D. Wagner. 1995. Platelets roll on stimulated endothelium in vivo: an interaction mediated by endothelial P-selectin. Proc. Natl. Acad. Sci. USA. 92:7450-7454.

43. Diacovo, T.G., K.D. Puri, R.A. Warnock, T.A. Springer, and U.H. von Andrian. 1996. Platelet-mediated lymphocyte delivery to high endothelial venules. Science (Wash. DC). 273:252-255.

44. Grober, J.S., B.L. Bowen, H. Ebling, B. Athey, C.G. Thompson, D.A. Fox, and L.M. Stoolman. 1993. Monocyte-endothelial adhesion in chronic rheumatoid arthritis. In situ detection of selectin and integrin interactions. J. Clin. Invest. 91:2609-2619.

45. Kubes, P., M. Jutila, and D. Payne. 1995. Therapeutic potential of inhibiting leukocyte rolling in ischemia/reperfusion. J. Clin. Invest. 95:2510-2519.
46. Lalor, P., and G.B. Nash. 1995. Adhesion of flowing leukocytes to immobilized platelets. Br. J. Haematol. 89:725-732.

47. Lorant, D.E., R.P. McEver, T.M. McIntyre, K.L. Moore, and S.M. Prescott. 1995. Activation of polymorphonuclear leukocytes reduces their adhesion to P-selectin and causes redistribution of ligands for P-selectin on their surfaces. J. Clin. Invest. 96:171-182.

48. Jones, D.A., O. Abbassi, L.V. McIntire, R.P. McEver, and W. Smith. 1993. P-selectin mediates neutrophil rolling on histamine-stimulated endothelial cells. Biophys. J. 65:1560-1569.

49. Waddell, T.K., L. Fialkow, C.K. Chan, T.K. Fishimoto, and G.P. Downey. 1995. Signaling functions of L-selectin. J. Biol. Chem. 270:1540315411.

50. Gawaz, M., F.J. Neumann, I. Ott, A. Schiessler, and A. Schömig. 1996. Platelet function in acute myocardial infarction treated with direct angioplasty. Circulation. 93:229-237.

51. Evangelista, V., P. Piccardoni, J.G. White, G. de Gaetano, and C. Cerletti. 1993. Cathepsin G-dependent platelet stimulation by activated polymorphonuclear leukocytes and its inhibition by antiproteinases: role of P-selectinmediated cell-cell adhesion. Blood. 81:2947-2957.

52. Colli, S., S. Eligini, M. Lalli, and E. Tremoli. 1996. Platelet-neutrophil interaction and superoxide anion generation: involvement of purine nucleotides. Free Rad. Biol. Med. 20:271-278.

53. Nagata, K., T. Tsuji, N. Todoroki, Y. Katagiri, K. Tanoue, H. Yamazaki, N. Hanai, and T. Irimura. 1993. Activated platelets induce superoxide anion release by monocytes and neutrophils through P-selectin. J. Immunol. 151:32673273

54. Elstad, M.R., T.R. La Pine, S. Cowley, R.P. McEver, T.M. McIntyre, S.M. Prescott, and G.A. Zimmerman. 1995. P-selectin regulates platelet-activating factor synthesis and phagocytosis by monocytes. J. Immunol. 155:21092122

55. Maugeri, N., V. Evangelista, A. Celardo, G. Dell'Elba, N. Martelli, P. Piccardoni, G. de Gaetano, and C. Cerletti. 1994. Polymorphonuclear leukocyte-platelet interaction: role of $\mathrm{P}$-selectin in thromboxane $\mathrm{B} 2$ and leukotriene C4 cooperative synthesis. Thromb. Haemostasis. 72:450-456.

56. Suzuki, H., S. Miura, H. Imaeda, M. Suzuki, J.Y. Han, M. Mori, D. Fukumura, M. Tsuchiya, and H. Ishii. 1996. Enhanced levels of chemiluminescence and platelet activating factor in urease-positive gastric ulcers. Free Radical Biol. Med. 20:449-454. 